\title{
Ban on Sale of Loose Cigarettes: Awareness, Perceptions and Practices among Vendors and Smokers in Karnataka, India
}

\author{
K Eshwari ${ }^{1}$, Muralidhar M Kulkarni ${ }^{2}$, Rohith Bhagawath ${ }^{3}$, Somya Mullapudi ${ }^{4}$, Tarun Selvarajan ${ }^{5}$, Veena G Kamath ${ }^{6}$
}

${ }^{1}$ Assistant Professor, Department of Community Medicine, Kasturba Medical College, Manipal Academy of Higher Education, Manipal- 576104; ${ }^{2}$ Associate Professor, Department of Community Medicine, Kasturba Medical College, Manipal Academy of Higher Education, Manipal- 576104; ${ }^{3}$ social Scientist, Department of Community Medicine, Kasturba Medical College, Manipal Academy of Higher Education, Manipal- 576104; ${ }^{4} \mathrm{PhD}$ Student, Department of Community Medicine, Kasturba Medical College, Manipal Academy of Higher Education, Manipal- 576104; ${ }^{5}$ UG Student, MBBS, Kasturba Medical College, Manipal Academy of Higher Education, Manipal- 576104; ${ }^{6}$ Professor, Department of Community Medicine, Kasturba Medical College, Manipal Academy of Higher Education, Manipal- 576104

\begin{tabular}{|c|c|c|c|c|c|c|c|}
\hline Abstract & Introduction & Methodology & Results & Conclusion & References & Citation & Tables / Figures \\
\hline \multicolumn{8}{|c|}{ Corresponding Author } \\
\hline \multicolumn{7}{|c|}{$\begin{array}{l}\text { Dr. Muralidhar M Kulkarni, Associate Professor, Department of Community Medicine, Kasturba Medica } \\
\text { College, Manipal Academy of Higher Education, Manipal, Karnataka, India- } 576104 \\
\text { E Mail ID: murali.kulkarni@manipal.edu }\end{array}$} & 口itis \\
\hline
\end{tabular}

\section{Citation}

Eshwari K, Kulkarni MM, Bhagawath R, Mullapudi S, Selvarajan T, Kamath VG. Ban on Sale of Loose Cigarettes: Awareness, Perceptions and Practices among Vendors and Smokers in Karnataka, India. Indian J Comm Health. 2020;32(2):394-398.

Source of Funding: District Tobacco Control Cell (DTCC), Udupi Conflict of Interest: None declared

\section{Article Cycle}

Received: 09/05/2020; Revision: 20/05/2020; Accepted: 05/06/2020; Published: 30/06/2020

This work is licensed under a Creative Commons Attribution 4.0 International License.

\section{Abstract}

Background: The Government of Karnataka banned loose cigarettes sale effect from September 2017 and is punishable under Cigarettes and Other Tobacco Products Act (COTPA) with fine and imprisonment in case of violation. Aim \& Objective: Study aims to assess awareness, perceptions and practices about ban among tobacco vendors and smokers. Methods and Material: Cross sectional survey was carried using pre-tested questionnaire to collect information regarding awareness about ban among vendors and smokers. Data were analyzed using SPSS version 15.0. Results: Ninety-five percent of the tobacco vendors continued to sell loose cigarettes despite the ban. Among vendors, $49.7 \%$, were aware of ban and of them $53.5 \% \mathrm{knew}$ it is a punishable offense. Vendors opined that they would stop selling loose cigarettes if ban is strictly enforced with frequent checks on periodical basis. One-fourth smokers opined they will reduce cigarettes consumption with few making an attempt to quit. Conclusions: Awareness about ban on sale of loose cigarettes was unsatisfactory among vendors and smokers including lack of knowledge regarding legal actions in case of violation. However, vendors responded favorably towards obeying the law. Smokers are likely to reduce or even quit smoking if the law is strictly enforced which highlights the need for creating awareness drives and strong enforcement of the policy.

\section{Keywords}

Loose cigarettes; Ban; Legal; Tobacco vendors; Smokers

\section{Introduction}

Sale and use of single cigarettes (also called singles or loose cigarettes) is widely common among people from low and middle-income countries including India. (1) According to Global Adult Tobacco survey most cigarettes purchased in Philippines, Bangladesh and India are sticks instead of packs. (2) A survey among African-American young adults belonging to poor socioeconomic status reported more than $75 \%$ preferred singles and reported reasons were convenience of purchase and low cost. (3) In
India, three fourth cigarettes are sold individually on smoker's demand. (4) It is well documented that sale of singles is associated with increased accessibility among minors, adolescents, less educated and lower - income smokers with major contribution to addiction among young which is potentially a great concern to field of tobacco control. (5) Also, very objective of pictorial health warnings and purpose of levying high tax on cigarette pack is lost on purchase of loose cigarettes. (6)

Street vendors involved in sale of loose cigarettes in India come under informal economic sectors, which are 
unrecognized, unrecorded and unregulated by legal system posing major challenge in tobacco control. (7) Also, vendors find it as an opportunity to extract more toll with singles and for tobacco companies, sale of singles have been an encouragement towards newer brands at point of sale. (6)

Article 6 of World Health Organization's Framework Convention on Tobacco Control (FCTC) recommends comprehensive policies and effective enforcement strategies to eliminate loose cigarette sale. (8) India being a signatory is still facing challenges in implementing regulation of ban on sale of loose cigarettes and related legal implications. However loose cigarettes sale has been banned in couple of states from North India. (9) In line with this, the Government of Karnataka also introduced law banning sale of loose cigarettes with effect from September 11, 2017 with provisions for punishment in case of violations. $(9,10)$

Hence, this research was planned to study loose cigarette sale in the community with respect to awareness, attitudes and practices among smokers and vendors and its likely impact on smoking habit.

\section{Aims \& Objectives}

\section{Aim:}

Assessment of Knowledge, Attitude and Practices towards ban on sale of loose cigarettes and related legal actions among vendors and smokers from Udupi district, Karnataka

Objectives:

1. Assessment of Knowledge, Attitude and Practices towards ban on sale of loose cigarettes and related legal actions among vendors and smokers

2. To determine the factors influencing the Knowledge, Attitude and Practices

\section{Material \& Methods}

Study type: Cross sectional epidemiological study

Study population: Vendors and smokers at points of tobacco sale

Study area: Present study was carried out in Udupi, a coastal district in Karnataka that has been previously selfdeclared to be high compliance for implementation of COTPA and has been able to effectively implement tobacco control programmes.

Sample size: Considering awareness regarding ban on sale of loose cigarettes to be $50 \%$ among vendors and smokers (based on a pilot survey), with $10 \%$ relative precision at $95 \%$ confidence level and a non-response rate of $20 \%$ the sample size worked out as 120 and 440 respectively. As the blocks are homogenous it was decided to recruit 30 vendors and 90 smokers from each block.

Methodology: The district was divided in to five blocks and from each block, shops selling tobacco products were considered as sampling frame. The first vendor shop was chosen at random and successive shops were visited by moving in particular direction in the locality till adequate number of vendors were included. All efforts were taken to ensure equal representation of vendors and smokers as per required sample size in each category, across blocks. At each outlet, besides a vendor, 2-3 cigarette smokers were requested to answer questions regarding awareness and impact of the law.

Institutional ethics committee approval was obtained before the initiation of study (IEC 882/2018). After obtaining written informed consent from participants, a pre-designed and pre-tested questionnaire was administered by trained interviewer to collect required information. The questionnaire tool was framed in such a way that it included assessment of knowledge, perceptions and practices of vendors and smokers regarding prohibitions on sale of loose cigarettes and related legal actions in case of violation. In addition, basic socio-demographic characteristics such as age, gender, locality and educational status were also noted.

Data analysis: The data were entered and analyzed using SPSS version 15.0. The continuous variables have been presented as mean and standard deviation whereas categorical data as frequency and percentage.

Operational definition: A current smoker was defined as a person who has smoked 100 cigarettes in his or her lifetime and who currently smokes cigarettes.

A tobacco vendor was defined as any person selling tobacco products for a period of at least one year.

\section{Results}

A total of 155 vendors and 465 smokers were interviewed. Of the 155 vendors interviewed, $75.4 \%$ completed secondary schooling followed by 22 (14.1\%) up to primary, while a few vendors were diploma graduates (8.4\%). About 148 (95.5\%) vendors reported selling loose cigarettes for the last 6-15 years with an average sale of 11-20 cigarettes per day. With respect to point of sale, $47.8 \%$ of vendor shops selling loose cigarettes were general stores followed by petty shops (41.3\%) and to a smaller extent, hotels, ice cream parlour and bakery. Majority $(81.9 \%)$ of vendors were of the opinion that their customers for single cigarettes were more often adult men and a few 28 (18.1\%) also mentioned college students.

Of the 148 (95.5\%) vendors reporting sale of loose cigarettes, only half ( $\mathrm{N}=77$ ) were aware of existence of a law banning sale of loose cigarettes. However, only 20 (25.9\%) of them mentioned that it has been enforced in Udupi district. Among vendors who were aware about the ban, only a half knew it was a punishable offense. Inspite of that, they continued selling loose cigarettes citing demand by the customers as the most common reason (74.2\%) as depicted in (Figure 1). It is interesting to note that two vendors even stated absence of health warnings as the reason for sale of loose cigarettes. A large proportion of vendors, $84.5 \%$ admitted that they will stop 
selling loose cigarettes if law banning sale of loose cigarettes is strictly enforced in the district.

The socio-demographic characteristics of smokers has been depicted in (Table 1), the mean ( $\pm S D$ ) age of the smokers included in the study is 35 years $( \pm 11.7)$. About 441 (94.8\%) smokers preferred loose cigarettes over packs and of them $294(66.7 \%)$ stated that singles cost less and 141 (32\%) said ease of buying singles as the reasons for their preference. Even the college students quoted similar reasons for preferring loosies. Only $39.4 \%$ of the smokers were aware about the law banning sale of loose cigarettes in the district. Their opinion on smoking behaviour, if there is strict enforcement of law was, $22 \%$ smokers said that they would cut down the number of cigarettes, while $16 \%$ contemplated to quit and $9.5 \%$ admitted they would give up smoking.

\section{Discussion}

A major public health challenge, in the current scenario, is tobacco control. Multipronged approach by government towards control of this epidemic including ban on sale of loose cigarettes is commendable. However, due to lack of awareness and laxity in implementation, legislative measures fail to contribute to further tobacco control efforts in the society. This is well depicted in a study by Hall MG et al in Mexico that reports substantial increase in loose cigarette sale that could be attributed to a strong tobacco environment in that country (11) and Latkin el in India which reports sale of singles to be quite common.

(12)

In a study by Stillman et al, $77 \%$ of the participants preferred loose cigarettes in the previous month whereas in the present study the proportion was much higher, $94.8 \%$ and this could be due to poor implementation of law banning sale of loose cigarettes.(3) Thrasher JF et al have documented much lesser proportion (38\%) of smokers choosing loose cigarettes which was in contrary to present study result.(13) Reasons for observed lower prevalence could be because singles are relatively less common in developed countries than in Low and Middle Income Countries (LMICs) including India. The loose cigarettes sold without health warnings often evade taxes and are favored by youth and this observation was in concurrence with present study result. (14) The documented proportion of young people preferring loose cigarettes by Thrasher at al was $18 \%$ and was in agreement with present study. (13)

Although, $69.7 \%$ of the smokers felt that they would smoke more if they buy a cigarette pack, this needs to be interpreted in the background of excess money they need to pay for each cigarette pack which could be a deterrent for buying the packs. Besides, effective health warning on cigarette packs, warnings even on cigarettes could help in creating awareness and could lead to positive behaviour change and that demands further research. Around $22 \%$ smokers expressed their will to reduce number of cigarette consumption and about $16 \%$ said they will think of quitting if law is enforced strictly and similar responses have been documented in other studies assessing the probable impact of ban on loose cigarettes among smokers from different geographical areas. $(11,13,15)$ Although, proportion of smokers who reported to quit smoking is not high but this result is definitely more than the average quit rate of about $7 \%$ among both smoke and smokeless tobacco users as reported in global tobacco epidemic report of 2017 by the World Health Organization. In contrary to above findings, WHO in its report also states that $31 \%$ of the smokers would still choose a packet of cigarette if there is non-availability of loose cigarettes and this finding emphasizes need for multi-pronged approach to reduce tobacco use in community. (16) This further demonstrates that regulatory approaches could play an important role in tobacco control and proportion of smokers with a positive attitude towards quitting smoking can be increased with uniform implementation of law. (16)

As shown in Table 1, mean ( $\pm S D$ ) age of smokers included in study is 35 years $( \pm 11.7)$. About 441 (94.8\%) smokers preferred loose cigarettes over packs and of them 294 (66.7\%) stated that singles cost less and 141 (32\%) said ease of buying singles as the reasons for their preference. Even college students quoted similar reasons for preferring loosies. Only $39.4 \%$ of the smokers were aware about law banning sale of loose cigarettes in the district. Their opinion on smoking behaviour, if law is strictly enforced was cut down number of cigarettes in $22 \%$ of smokers, while $16 \%$ contemplated to quit and $9.5 \%$ would give up smoking.

\section{Conclusion}

Though awareness about ban on sale of loose cigarettes and the legal implications of violation of law was unsatisfactory among vendors and smokers, a large proportion of vendors admitted to stop selling loose cigarettes if law is enforced. College students form considerable proportion of customers for loose cigarettes and ban on these can aid in preventing smoking uptake among young people. Smokers believe loose cigarettes cut down expenses on smoking that needs to be explored through further studies.

\section{Recommendation}

There is a need to create awareness regarding law banning sale of loose cigarettes through print and electronic media specifically among the stakeholders and community in general and ensure strict and uniform implementation.

\section{Limitation of the study}

Due to time and feasibility constraints interviewers could only enquire regarding the sale of loose cigarettes and could not verify the practices at all shops. However, as the participants were assured of anonymity, the study results 
are unlikely to be different from the current scenario in the district.

\section{Relevance of the study}

The present study and similar studies across the globe have highlighted the influence of loose cigarettes in youth addiction to tobacco products. The ease of purchase, cost effective nature and as a cut back strategy among smokers have made the practice of sale of loose cigarettes rampant. As part of implementation of ban there needs to be equal importance in raising awareness among the vendors and smokers regarding the ban which can lead to its uniform and effective implementation. A multipronged approach to control tobacco is essential and can be strengthened by stringent implementation of the law on ban on sale of loose cigarettes and other laws.

\section{Authors Contribution}

EK and MMK conceptualized the study. RB and MS developed the protocol and questionnaire with the help of VGK. MS and TS played a vital role in data collection. Data analysis and interpretation was done by MMK, EK VGK. EK, TS and MS developed the first draft of the manuscript which was edited by MMK and VGK. All authors read the manuscript and approved it for submission to the journal.

\section{Acknowledgement}

Authors are grateful to the Department of Community Medicine, KMC, Manipal and District Tobacco Control Cell for their support in carrying out this study.

\section{References}

1. World Health Organization. Framework Convention on Tobacco Control. 2013.

2. Kostova D, Chaloupka FJ, Yurekli A, Ross H, Cherukupalli R, Andes L, Asma S. A cross-country study of cigarette prices and affordability: evidence from the Global Adult Tobacco Survey. Tob Control. 2014 Jan;23(1):e3. doi: 10.1136/tobaccocontrol-2011-050413. Epub 2012 Aug 25. PubMed PMID: 22923477. [PubMed].

3. Stillman FA, Bone L, Avila-Tang E, Smith K, Yancey N, Street C, Owings K. Barriers to smoking cessation in inner-city African American young adults. Am J Public Health. 2007 Aug;97(8):14058. doi: 10.2105/AJPH.2006.101659. Epub 2007 Jun 28. PubMed PMID: 17600247; PubMed Central PMCID: PMC1931448.[PubMed].

4. Siddiqui Z. India moves towards ban on loose cigarettes to deter smoking (Internet). 25th November 2014. Available at URL: https://www.reuters.com/article/us-india-cigarettes/india-movestoward-ban-on-loose-cigarettes-to-deter-smokingidUSKCNOJ91MP20141125.

5. Green MP, McCausland KL, Xiao H, Duke JC, Vallone DM, Healton CG. A closer look at smoking among young adults: where tobacco control should focus its attention. Am J Public Health. 2007
[Ban on Sale of]... | Eshwari K et al Aug;97(8):1427-33. doi: 10.2105/AJPH.2006.103945. Epub 2007 Jun 28. PubMed PMID: 17600242; PubMed Central PMCID: PMC1931459.[PubMed].

6. Lal P, Kumar R, Ray S, Sharma N, Bhattarcharya B, Mishra D, Sinha MK, Christian A, Rathinam A, Singh G. The Single Cigarette Economy in India--a Back of the Envelope Survey to Estimate its Magnitude. Asian Pac J Cancer Prev. 2015;16(13):5579-82. doi: 10.7314/apjcp.2015.16.13.5579. PubMed PMID: 26225713. [PubMed].

7. de Ojeda A, Barnoya J, Thrasher JF. Availability and costs of single cigarettes in Guatemala. Nicotine Tob Res. 2013 Jan;15(1):83-7. doi: 10.1093/ntr/nts087. Epub 2012 Apr 6. PubMed PMID: 22492083. [PubMed].

8. World Health Organization, Summary Report on global progress in implementation of the WHO Framework Convention on Tobacco Control. Geneva, Switzerland.WHO;2009.

9. Niranjan K N. Karnataka Government Bans Sale of Loose Cigarettes, Tobacco Products with immediate effect (Internet). Bangalore mirror. Available at URL: http://bangaloremirror.indiatimes.com/bangalore/others/bangal ore/others/bengaluru-ban-on-loose-sale-of-cigarettes-tobaccoproducts-with-immediate-effect/articleshow/60859886.cms.

10. The Hindu. Karnataka bans sale of loose cigarettes. Sep 28th 2017. Available at URL: http://www.thehindu.com/news/national/karnataka/karnatakabans-sale-loose-cigarettes/article19765570.ece. Accessed on April $17,2020$.

11. Hall MG, Fleischer NL, Reynales-Shigematsu LM, Arillo-Santillán E, Thrasher JF. Increasing availability and consumption of single cigarettes: trends and implications for smoking cessation from the ITC Mexico Survey. Tob Control. 2015 Jul;24 Suppl 3:iii64-iii70. doi: 10.1136/tobaccocontrol-2014-051690. Epub 2014 Sep 5. PubMed PMID: 25192772; PubMed Central PMCID: PMC4465400. [PubMed].

12. Latkin C, Murray L, Clegg KM. The prevalence and correlates of single cigarette selling among urban disadvantaged drug users in Baltimore, Maryland. Drug Alcohol Depend. 2013; 132:466-470.

13. Thrasher JF, Villalobos V, Dorantes-Alonso A, Arillo-Santillán E, Cummings KM, O'Connor R, Fong GT. Does the availability of single cigarettes promote or inhibit cigarette consumption? Perceptions, prevalence and correlates of single cigarette use among adult Mexican smokers. Tob Control. 2009 Dec;18(6):431-7. doi: 10.1136/tc.2008.029132. Epub 2009 Aug 10. PubMed PMID: 19671535; PubMed Central PMCID: PMC2778078.[PubMed].

14. Baker HM, Lee JG, Ranney LM, Goldstein AO. Single Cigarette Sales: State Differences in FDA Advertising and Labeling Violations, 2014 United States. Nicotine Tob Res. 2016 Feb;18(2):221-6. doi: 10.1093/ntr/ntv053. Epub 2015 Mar 5. PubMed PMID: 25744967; PubMed Central PMCID: PMC4723674.[PubMed].

15. Smith KC, Stillman F, Bone L, Yancey N, Price E, Belin P, Kromm EE. Buying and selling "loosies" in Baltimore: the informal exchange of cigarettes in the community context. J Urban Health. 2007 Jul;84(4):494-507. doi: 10.1007/s11524-007-9189-z. PubMed PMID: 17431795; PubMed Central PMCID: PMC2219569.[PubMed].

16. WHO report on the global tobacco epidemic 2017. Tobacco Free Initiative (TFI). Available at URL: http://www.who.int/tobacco/global_report/2017/en/. Accessed on April 17, 2020.

\section{Tables}

TABLE 1 SOCIO-DEMOGRAPHIC DETAILS OF SMOKERS ( $\mathrm{N}=465$ )

\begin{tabular}{|c|l|}
\hline Characteristics & Frequency (\%) \\
\hline Age (years) & $217(46.7)$ \\
\hline $15-30$ & $172(37)$ \\
\hline $31-45$ & $57(12.2)$ \\
\hline
\end{tabular}




\begin{tabular}{|l|l|}
\hline Ge-85 & $19(4.1)$ \\
\hline Male & \\
\hline Female & $459(98.7)$ \\
\hline Education & $6(1.3)$ \\
\hline Illiterate/can read & $9(1.9)$ \\
\hline Primary schooling $\left(1^{\text {st }}-4^{\text {th }}\right.$ std) & $33(7.1)$ \\
\hline Secondary schooling $\left(5^{\text {th }}-12^{\text {th }}\right.$ std) & $321(69.0)$ \\
\hline Graduate/Diploma & $102(22.0)$ \\
\hline Occupation & \\
\hline Skilled & $226(48.6)$ \\
\hline Unskilled & $184(39.6)$ \\
\hline Unemployed & $27(5.8)$ \\
\hline Students & $28(6.0)$ \\
\hline
\end{tabular}

\section{Figures}

FIGURE 1 REASONS FOR CONTINUED SALE OF LOOSE CIGARETTES BY THE VENDORS. ( $\mathrm{N}=147)$

120

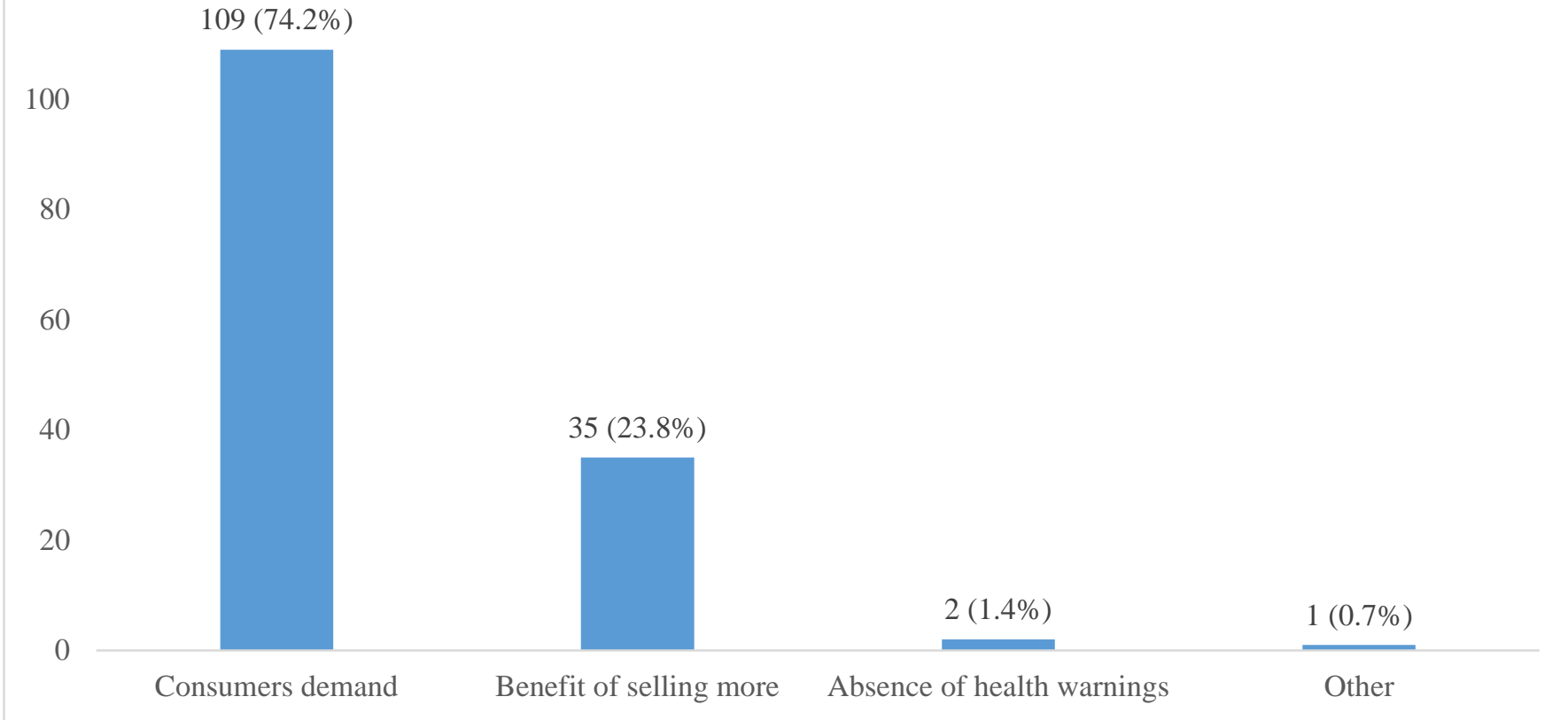

